\title{
Effects of the ms10 gene, polygenes and their interaction on pistil and anther-cone lengths in tomato flowers
}

\author{
ILIT LEVIN, AVIGDOR CAHANER, HAIM D. RABINOWITCH \& YONATAN ELKIND* \\ Faculty of Agriculture, Department of Field Crops, Vegetables and Genetics, The Hebrew University of Jerusalem, \\ PO Box 12, Rehovot 76100, Israel
}

\begin{abstract}
Pistil and anther-cone lengths (PL and AL) are important traits in tomato hybrid seed production with the use of male-sterile flowers and in fruit production of fertile plants under high temperature. The effects of the male sterility gene ms 10 , polygenes, and their interaction on tomato PL and AL and on the difference between them (DIF) were studied in two experimental populations, each obtained from a different cross and comprised of $\mathrm{F}_{3}$ families derived from selfed heterozygous $(M s 10 / \mathrm{ms} \mathrm{O}) \mathrm{F}_{2}$ plants. Data were analysed using a mixed model for a single gene, polygenes, and their interaction. The presence of the $m s 10$ gene resulted in AL and PL that were shorter by 2.5 $( \pm 0.1) \mathrm{mm}$ and $1.2( \pm 0.1) \mathrm{mm}$, respectively, in male-sterile flowers than in male-fertile ones. Thus DIF was greater by $1.3( \pm 0.1) \mathrm{mm}$ in male-sterile flowers than in male-fertile flowers. 'Main polygenic variance' was found in all three traits. The variance due to interaction between polygenes and the ms 10 gene, even when significant, was always smaller than the variance due to polygenes alone, or to environment. Emasculation of the $m s 10$ male-sterile parent appears to be unavoidable for the efficient production of hybrid seeds.
\end{abstract}

Keywords: anther-cone, male sterility, ms 10, pistil, single gene $\times$ polygene interaction, tomato.

\section{Introduction}

Male sterility, which in tomato is controlled by a single recessive gene, reduces the cost of hybrid seed production by eliminating the need to emasculate the female parent prior to anthesis (Rick \& Robinson, 1951; Lapushner \& Frankel, 1967; Scott et al., 1980; Yordanov, 1983; Stevens \& Rick, 1986).

Pistil and anther-cone lengths (PL and AL) are highly important characteristics of the female flower in the production of tomato hybrid seeds. An exserted pistil in the male-sterile flower facilitates efficient hand pollination, whereas stigma inserted within the anthercone necessitate removal of the anther-cone prior to pollination (Philouze, 1969; Scott et al., 1980). On the other hand, self-pollination of the hybrid plants, necessary for yield production, requires a pistil that is shorter than the anther-cone. Exserted pistils in tomato have been associated with poor fruit set, which is often enhanced by high temperatures (Philouze, 1969; Levy et al., 1978; Scott et al., 1980).

*Correspondence.
PL and AL have been described as quantitative traits with continuous distributions (Scott et al., 1980). $\mathrm{AL}$ was found to be controlled by a few polygenes, with complete dominance of the longer cone (Georgiev \& Atanassova, 1980). Hanna (1980) found partial dominance of short styles and 73 per cent heritability of style length. Significant variance in both general and specific combining abilities was found for PL and AL in an $8 \times 8$ diallel experiment (Atanassova, 1978).

The difference (DIF) between PL and AL is controlled by two to 20 polygenes, the number depending on the genotype and experimental conditions, with partial dominance of the exserted pistil. A dominance coefficient of 0.76 towards an exserted pistil has been reported (Currence, 1944; Ruttencutter \& George, 1975; Scott et al., 1980). Other experiments have found 34 and 43 per cent heritability of the exserted pistil length (Rick \& Dempsey, 1969; Levy et al., 1978).

The single gene, ms 10 , which controls male sterility in tomato, is widely used in hybrid seed production (Philouze, 1970, 1974; Yordanov, 1983). This gene also causes shortening of the pistil and the anther-cone. 
A mixed model incorporating the effects of a single gene, polygenes, and the interaction between them was proposed by Elkind \& Cahaner (1986). Components of the model are estimated by the use of an experimental design composed of $\mathrm{F}_{3}$ families derived from selfed $F_{2}$ plants heterozygous for the single gene in question. The purpose of the present work was to use this experimental design to estimate the effects of the ms 10 gene, polygenes, and their interaction on PL and $\mathrm{AL}$ and their DIF.

\section{Materials and methods}

\section{Experimental populations}

Four parental lines were used, two with male-fertile flowers $\left(\mathrm{P}_{1}\right.$ and $\left.\mathrm{P}_{2}\right)$ and two with male-sterile flowers $\left(\mathrm{P}_{3}\right.$ and $\left.\mathrm{P}_{4}\right)$. The male-sterile lines also carried the anthocyanin-absent allele $a a$, which is closely linked $(1.7 \pm 1.1 \mathrm{cM})$ to the $m s 10$ gene (Philouze, 1974). The parental lines were in an $\mathrm{F}_{5}$ generation with determinate growth habit $(s p / s p)$. The $\mathrm{P}_{3}$ and $\mathrm{P}_{4}$ lines were derived from self-pollinated heterozygous (Ms10) $m s 10)$ plants, and thus included all three ms 10 genotypes.

Male-sterile plants of $\mathrm{P}_{3}$ and $\mathrm{P}_{4}$ were used to prepare the $F_{1}$ hybrids. Self-pollination of the $F_{2}$ plants heterozygous for $m s 10$ from the crosses $\mathrm{P}_{1} \times \mathrm{P}_{3}$ and $\mathrm{P}_{2} \times \mathrm{P}_{4}$ produced the experimental $F_{3}$ populations, 1 and 2, respectively. Offspring of $\mathrm{F}_{2}$ plants heterozygous for the $m s 10$ gene formed an $\mathrm{F}_{3}$ family. The $\mathrm{F}_{3}$ populations 1 and 2 were composed of 20 and 27 families, respectively.

\section{Experimental procedures}

The experiment was conducted using a split-plot design in two randomized blocks, with one main plot for each family per block. Within each main plot (family), plants with the same ms10 genotype were grouped into the same sub-plot. Each family consisted of about 33 plants.

Identification of the mslO genotype in $\mathrm{F}_{2}$ and $\mathrm{F}_{3}$ male-sterile plants was according to sterile phenotype. In the male-fertile plants, ms 10 genotype was determined in young seedlings using the tight linkage between $a a$ and $m s 10$ genes (Philouze, 1974), and also by progeny testing in the field. One-week-old, darkroom-grown $\left(25^{\circ} \mathrm{C}\right)$ seedlings from each male-fertile plant were exposed to intense light for $24 \mathrm{~h}$, and then scored for green and purple colour.

$\mathrm{PL}$ and $\mathrm{AL}$ of flowers at anthesis were measured in six flowers per plant. The lengths were measured from the base of the ovary to the top of the stigma or stamens, and DIF was obtained by subtraction of $\mathrm{AL}$ from PL.

\section{Data analysis}

PL, AL and their DIF were analysed according to the mixed model for a single gene, polygenes and their interaction, in a split-plot design (Elkind \& Cahaner, 1986):

$$
Y_{i j l k}=\mu+F_{j}+B_{l}+(F B)_{j l}+\beta_{i}+(\beta F)_{i j}+(\beta B)_{i l}+W_{i j l k}(1)
$$

where $Y_{i j l k}$ is the trait mean of flowers from plant $k$ with the $m s l 0$ genotype $i$ of family $j$, grown in block $l$; $\mu$ is the general mean; $F_{j}$ is the effect of family $j$, $j=1 \ldots f(f=$ number of families $)$, each family being a randomly sampled combination of polygenes; $B_{l}$ is the effect of block $l(l=1$ or 2$) ;(F B)_{j l}$ is the family by block interaction; $\beta_{\mathrm{i}}$ is the effect of the ms 10 genotype $i$, with three possible genotypes; $(\beta F)_{i j}$ is the $m s 10$ by family (polygenes) interaction; $(\beta B)_{i l}$ is the $m s 10$ by block interaction; $W_{i j l k}$ is the 'residual' effect of plant $k$ within the $m s 10$ genotype $i$, family $j$ and block $l, k=1 \ldots k$ ( $k$ is the number of plants in every combination of family $j$, ms 10 genotype $i$, and block $l$ ). $\mu$ and $\beta_{i}$ were considered 'fixed' effects, while the rest of the effects were 'random'. The variance between the families represents variance between polygenes.

Variance was analysed by the restricted maximum likelihood method, with program $3 \mathrm{~V}$ of the BMDP (Dixon et al., 1985). Hypothesis testing was accomplished by calculation of the difference, distributed as chi-square with one degree of freedom (Dixon et al., 1985), between $-2 \times \log$ of maximum likelihood of the complete model and that of a model in which the tested component was absent.

Heterogeneity of the slopes of the three $\mathrm{ms} 10$ genotype means within families over family means was analysed by using joint regression analysis (Elkind \& Cahaner, 1986). The family means and the mean of each msl0 genotype in every family were the 'leastsquare means' (Sokal \& Rohlf, 1981). The null hypothesis of homogeneous slopes was tested by the use of the following model:

$Y_{i j}=\mu+\beta_{i}+Y_{\cdot j}+b_{i}\left(Y_{\cdot j}\right)+W_{i j}$

where $Y_{i j}$ is the trait mean of plants with the $m s 10$ genotype $i$ from family $j$; $\mu$ is the general mean; $\beta_{i}$ is the effect of the ms 10 genotype $i ; Y_{. j}$ is the mean of family $j ; b_{i}$ is the regression coefficient of the mean $m s 10$ genotype $i$ within families over family means, and $W_{i j}$ is the error term. $Y_{i j}$ was weighted by the inverse of its standard error. Slope heterogeneity was also observed in 'single gene/family' plots (Elkind \& Cahaner, 1986) in which $Y_{i j}$ is plotted against $Y_{. \mathrm{j}}$. The 
means of the msl0 genotypes were 'least-square means' (SAS, 1985).

The additive $(a)$ effect of the mslO gene was calculated as half of the difference between the two homozygotes, and the dominance $(d)$ effect as the difference between the heterozygotes and the mean of the two homozygotes.

'Net polygenic heritability' (Elkind \& Cahaner, 1986 ), representing heritability in the $F_{3}$ generation due to polygenes, independent of the $m s 10$ gene effect, was calculated according to Cahaner \& Hillel (1980) for traits in cases where the additive-dominance model was not rejected by the joint scaling test (data not shown).

\section{Results}

In both populations the effect of the ms 10 gene was significant for all three traits. The Mslo fertile allele exhibited complete dominance in all three traits, $d$ similar to $a$ (Table 1). The PL and AL of the sterile genotype $(\mathrm{ms} / 0 / \mathrm{ms} / 0)$ were $1.2 \mathrm{~mm}$ and $2.5 \mathrm{~mm}$ shorter, respectively, than either of the fertile genotypes (Msl0/Mslo, Msl0/msl0). Thus, DIF was 1.3 $\mathrm{mm}$ greater in sterile than in fertile flowers. This can also be observed in ' $m s 10 /$ family' graphs (Fig. 1a-f). The means of the Mslo/MslO and Mslo/mslo genotypes within families were greater than those of ms $10 /$ ms 10 genotypes for PL and AL, and smaller for DIF. Despite the large differences between the two populations in $m s 10$ genotype means for the analysed traits, $a$ and $d$ effects of the ms 10 gene were almost identical (Table 1).

Table 1 Mean and standard error (SE) of ms 10 genotypes for pistil length $(\mathrm{PL})$, anther-cone length $(\mathrm{AL})$ and the difference between them (DIF) $(0.1 \mathrm{~mm})$ in two independent populations

\begin{tabular}{|c|c|c|c|c|c|c|}
\hline \multirow[b]{2}{*}{ Variance source } & \multicolumn{2}{|c|}{ PL } & \multicolumn{2}{|c|}{$\mathrm{AL}$} & \multicolumn{2}{|c|}{ DIF } \\
\hline & Mean & SE & Mean & $\mathrm{SE}$ & Mean & SE \\
\hline \multicolumn{7}{|l|}{ Population 1} \\
\hline $\mathrm{ms} 10 / \mathrm{mslO}$ & 73.2 & 1.3 & 72.9 & 2.3 & 0.3 & 2.1 \\
\hline Mslo/mslo & 85.3 & 1.2 & 98.2 & 2.3 & -12.9 & 2.1 \\
\hline Ms $10 / M s 10$ & 85.3 & 1.3 & 98.4 & 2.3 & -13.1 & 2.1 \\
\hline$a$ & 6.1 & 0.5 & 12.7 & 0.4 & -6.7 & 0.6 \\
\hline$d$ & 6.1 & 0.5 & 12.5 & 0.4 & -6.5 & 0.5 \\
\hline \multicolumn{7}{|l|}{ Population 2} \\
\hline $\mathrm{msl} / \mathrm{msl} \mathrm{mo}$ & 92.6 & 0.8 & 72.2 & 0.9 & 20.4 & 1.2 \\
\hline $\mathrm{Ms} 10 / \mathrm{ms} 10$ & 104.8 & 0.8 & 97.2 & 0.8 & 7.6 & 1.2 \\
\hline MsIO/MsIO & 104.9 & 0.8 & 97.5 & 0.9 & 7.5 & 1.2 \\
\hline$a$ & 6.1 & 0.3 & 12.7 & 0.5 & -6.5 & 0.4 \\
\hline$d$ & 6.1 & 0.2 & 12.4 & 0.4 & -6.4 & 0.4 \\
\hline
\end{tabular}

$a=$ Additive effect, $d=$ dominance effect.
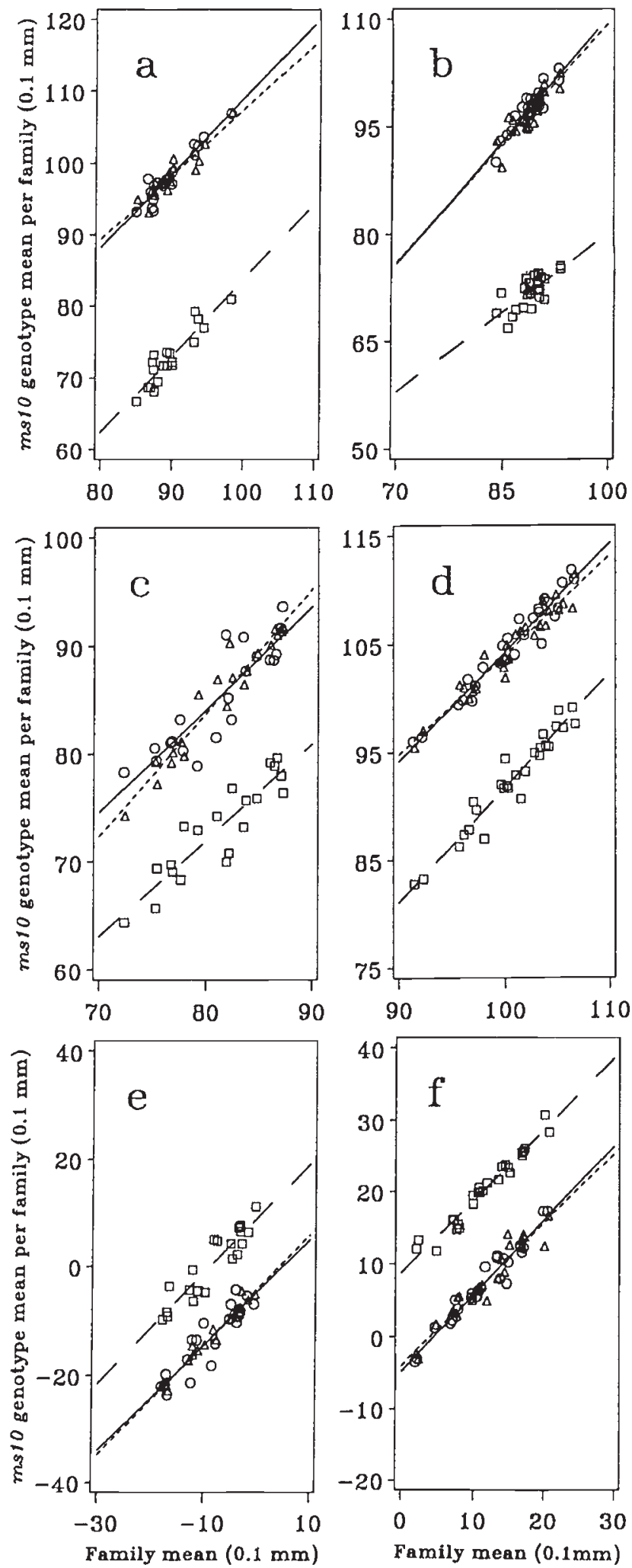

Fig. $1 \mathrm{~ms} 10$ by family plot for anther-cone length ( $\mathrm{a}$ and $\mathrm{b}$ ), pistil length ( $\mathrm{c}$ and $\mathrm{d}$ ) and the difference between them ( $\mathrm{e}$ and f) in populations 1 and 2, respectively. Means within each family of the $\mathrm{ms} 10$ gene are $\mathrm{ms} 10 / \mathrm{ms} 10 \square, \mathrm{Ms} 10 / \mathrm{ms} 10 \triangle$, and Ms $10 / M s 10 \circ$; observed regression lines are - - . and -, respectively. 
Table 2 Analysis of variance and estimates of variance components $\left(\sigma^{2}\right)$, their standard errors $(\mathrm{SE})$ and their chi-square probability $\left(\chi^{2}\right)$ for pistil length $(\mathrm{PL})$, anther-cone length $(\mathrm{AL})$ and the difference between them $(\mathrm{DIF})(0.1 \mathrm{~mm})$ in an ' $\mathrm{F}_{3^{-}}$ families' experiment using restricted maximum likelihood

\begin{tabular}{|c|c|c|c|c|c|c|c|c|c|}
\hline \multirow[b]{2}{*}{ Variance source } & \multicolumn{3}{|c|}{ PL } & \multicolumn{3}{|c|}{$\mathrm{AL}$} & \multicolumn{3}{|c|}{ DIF } \\
\hline & $\sigma^{2}$ & SE & $P\left(\chi^{2}\right)$ & $\sigma^{2}$ & $\mathrm{SE}$ & $P\left(\chi^{2}\right)$ & $\sigma^{2}$ & SE & $P\left(\chi^{2}\right)$ \\
\hline \multicolumn{10}{|l|}{ Population 1} \\
\hline Between families & 19.33 & 7.1 & 0.000 & 8.79 & 3.6 & 0.000 & 30.27 & 10.8 & 0.000 \\
\hline Block & 0.58 & 1.0 & NS & 9.50 & 13.7 & 0.015 & 5.13 & 7.4 & 0.023 \\
\hline Family by block & 1.48 & 0.9 & 0.009 & 2.67 & 1.1 & 0.000 & 1.36 & 0.9 & 0.017 \\
\hline $\mathrm{ms} 10$ by family & 3.35 & 1.3 & 0.000 & 1.22 & 0.6 & 0.001 & 4.46 & 1.6 & 0.000 \\
\hline$m s 10$ by block & 0.00 & - & NS & 0.13 & 0.3 & NS & 0.00 & - & NS \\
\hline Residual & 19.76 & 1.2 & & 12.53 & 0.7 & & 20.03 & 1.2 & \\
\hline \multicolumn{10}{|l|}{ Population 2} \\
\hline Between families & 14.19 & 4.4 & 0.000 & 1.48 & 1.4 & NS & 22.64 & 6.7 & 0.000 \\
\hline Block & 0.00 & - & NS & 0.81 & 1.5 & NS & 0.82 & 1.4 & NS \\
\hline Family by block & 1.69 & 0.8 & 0.001 & 3.76 & 1.3 & 0.000 & 1.15 & 0.7 & 0.025 \\
\hline$m s 10$ by family & 0.00 & - & NS & 1.64 & 0.6 & 0.000 & 0.45 & 0.5 & NS \\
\hline ms 10 by block & 0.00 & - & NS & 0.20 & 0.3 & NS & 0.17 & 0.3 & NS \\
\hline Residual & 20.24 & 1.0 & & 12.45 & 0.6 & & 21.72 & 1.1 & \\
\hline
\end{tabular}

'Between-families' variance was found to be significant for all traits, except for AL in population 2 (Table 2). This exception is reflected in Fig. $1 \mathrm{~b}$, where the range of family means for each of the mslo genotypes is smaller than for the other traits. The $m s l 0$ by family interactions were found to be significant for most traits, except for PL and DIF in population 2 (Table 2). The regression lines for the three ms 10 genotypes in each trait were parallel (Fig. 1a-f), and did not differ from one other (Table 3 ), indicating the absence of multiplicative $m s 10$ by family interaction. The means of the three ms 10 genotypes within families deviated from these lines in a random fashion.

For PL and the DIF the 'between-families' variance was about half of the total variance, and was similar for the two populations (Table 2). For AL the major sources of variance were 'between-families', blocks, and residual in population 1 , and residual in population 2 (Table 2). Variance due to $m s 10$ by family interaction was about 8 per cent and 0 per cent of the total variance for PL in populations 1 and 2, respectively; the corresponding proportions were 5 per cent and 11 per cent for AL and 7 per cent and 0 per cent for DIF. The estimated residual variance was similar in both populations for all three traits.

The 'net polygenic heritability', based on variance components within and between $\mathrm{F}_{3}$ families, is the ratio of polygenic variance to total phenotypic variance in the $\mathrm{F}_{3}$ generation, after removal of the msl0 effect. The calculated value was 0.62 for PL in population 2 . For cases with significant genetic interaction, but of small relative magnitude, the "net polygenic heritability"
Table 3 ANOVA of a joint regression analysis for heterogeneity of the slopes of $m s 10$ genotypes within family means over family means; sums of squares (SS) and $F$ values for pistil length (PL), anther-cone length (AL) and the difference between them (DIF) $(0.1 \mathrm{~mm})$

\begin{tabular}{|c|c|c|c|c|c|c|}
\hline & \multicolumn{3}{|c|}{ Population $1^{*}$} & \multicolumn{3}{|c|}{ Population $2 \dagger$} \\
\hline & SS & $F$ & $P(F)$ & SS & $F$ & $P(F)$ \\
\hline PL & 16.1 & 1.7 & 0.20 & 4.1 & 1.3 & 0.28 \\
\hline $\mathrm{AL}$ & 2.5 & 0.5 & 0.58 & 9.9 & 2.0 & 0.14 \\
\hline DIF & 3.4 & 0.3 & 0.74 & 1.3 & 0.3 & 0.74 \\
\hline
\end{tabular}

*With 2 and 32 degrees of freedom.

†With 2 and 50 degrees of freedom.

values serve as rough estimates only. They were: 0.74 for PL in population $1 ; 0.62$ for $\mathrm{AL}$ in population 1 , and no genetic variance was found for $\mathrm{AL}$ in population 2; for DIF the values were 0.90 and 0.76 in populations 1 and 2 , respectively.

\section{Discussion}

\section{The ms10 gene}

The mslo gene reduced both $\mathrm{PL}$ and $\mathrm{AL}$ in malesterile flowers relative to fertile ones, with greater reduction in the latter trait, as previously reported (Philouze, 1969, 1973). The DIF was therefore greater in male-sterile than in fertile flowers, which led in population 2 to a relatively more exserted stigma in 
male-sterile than in fertile flowers (Fig. 1f), as also reported by Philouze (1974). With other genetic backgrounds, such as families with high DIF in population 1, it can lead to an exserted stigma in male-sterile flowers and an inserted stigma in fertile ones (Fig. 1e). In all three traits, complete dominance of the male-fertile allele was found, in agreement with a previous report (Atanassova \& Georgiev, 1986).

Despite the differences in mean PL between the two populations, both additive and dominance effects of ms 10 on the three examined flower traits in the two populations were identical. Similarly, Elkind et al. (1990), using the same experimental design, found the additive and dominance effects of the nor gene on tomato fruit softness to be identical in two different populations. It is therefore concluded that the ' $\mathrm{F}_{3}$ families' experimental design facilitates accurate estimation of single gene effects on quantitative traits.

\section{'Main polygenic variance'}

The 'between-families' variance component was found to be significant in all cases, except that of AL in population 2. This component reflects polygenes acting in a similar manner (with respect to direction and size) on the three $m s 10$ genotypes, and is referred to hereafter as 'main polygenic variance'. For example, polygenic combinations that code for long pistils maintain their effect on pistil size in all three $m s 10$ genotypes. It seems that most of the continuous genetic variance is due to the main polygenic component (Table 2). This suggests that genetic information regarding these flower traits in fertile plants, obtained in other studies (Ruttencutter \& George, 1975; Atanassova, 1977; Hanna \& Hernandez, 1979; Scott et al., 1980), might apply to male-sterile plants as well. This is true, however, only when the magnitude of the 'between-families' variance is relatively large.

The existence of significant genetic interaction affects the relevance of heritability estimates for selection purposes, and such estimates should therefore be viewed with caution. In our study, PL and DIF in population 2 had no significant $m s 10$ by polygenes interaction. Significant polygenic interaction was detected for DIF by a joint scaling test (data not shown). Therefore, in population 2 the 'net polygenic heritability' could be estimated only for PL, and was 0.62 (calculated from Table 2). This value is similar to the estimate (0.72) reported by Hanna (1980) for fertile plants. Heritability estimates for population 1, in which little interaction was detected for each of the three traits, ranged from 0.6 to 0.9 .

\section{Variance due to $\mathrm{ms} 10$ by polygenes interaction}

The ms 10 by families interaction was found to be significant and random in nature for all traits in population 1 and for AL in population 2 (Table 2, Fig. 1). Such an interaction may result from polygenes that have different effects on each ms 10 genotype (Elkind \& Cahaner, 1986). This is the first description of such interaction between the ms 10 gene and polygenes for PL and AL. Significant random single-gene by polygenes interaction was found for the Rht gene and culm length in spring wheat (Baharav et al., 1992) and for the nor gene and tomato fruit softness (Elkind et al., 1990).

For population 1, although ms 10 by families interaction was found significant for all three traits, it contributed a relatively small part of the continuous genetic variance (12-15 per cent, calculated from Table 2). In population 2 the $m s 10$ by families interaction for $\mathrm{AL}$ was similar in magnitude to that in population 1 , but it was the major source of continuous genetic variation because the 'main polygenic variance' was very small (Table 2). This might indicate that the polygenes involved in the interactions are independent of those having the main effects.

Despite the relatively small variance due to the $m s 10$ by polygenes interaction, the ' $F_{3}$ family' experiment allowed its detection with a high level of significance. This demonstrates that an experiment of the size used in our experiment ( 20 families, 670 plants) has a sufficient power of test. Similar conclusions were reached in a computer simulation study (Elkind, unpublished results).

\section{Use of the ms10 gene in a tomato breeding programme}

Many modern fresh-market tomato varieties are hybrids, and the percentage of hybrid varieties for processing is on the rise. Male sterility greatly reduces the production costs of hybrid seeds (Lapushner \& Frankel, 1967; Scott et al., 1980; Yordanov, 1983). An exserted pistil in the male-sterile flower eliminates the need for emasculation prior to pollination, and further reduces production costs. On the other hand, only inserted pistils can ensure good self-pollination and successful fruit set of the hybrid plants cultivated under high temperatures (Levy et al., 1978; Hanna, 1980). Thus the ideal flower type for seed production differs markedly from that of the commercial hybrid plants.

Theoretically this conflict can be solved using one of the following genetic options: (1) a male-sterile gene that codes for long pistil and/or short anther-cone; $(2)$ a polygenic combination that controls exserted pistil in male-sterile flowers and inserted pistil in fertile 
flowers; (3) a male-sterile female line with polygenes for exserted pistils and a male line with a polygenic combination producing inserted pistils in the hybrid.

In this study, the effect of the mslO gene seems to fulfil the requirements of the first option by reducing AL more than PL. In a certain polygenic combination this will result in stigma exsertion of about $0.6 \mathrm{~mm}$ in the male-sterile flower and stigma insertion of about $0.6 \mathrm{~mm}$ in a fertile flower (Table 1). However, high temperatures, which cause even greater stigma exsertion (Levy et al., 1978), may lead to exserted stigmas in fertile flowers. The $m s 10$ gene is therefore insufficient for option (1). Because of the small variance due to the $m s 10$ by polygenes interaction, the second option is inapplicable given the genetic variation present in this experiment. This option might be useful only if a larger genetic variation for $m s 10$ by polygenes interaction could be detected and introduced into the breeding material. The third option might be of practical value, since additive polygenic variance was found for the DIF. However, others have reported dominance of exserted pistil (Ruttencutter \& George, 1975; Atanassova, 1977; Scott et al., 1980), and in such populations the third option would therefore be inapplicable.

It thus seems that emasculation of the $m s 10$ malesterile parent is unavoidable in most cases for hybrid seed production. Possible alternatives to this process are seed production under high temperatures or application of gibberellic acid in order to increase PL (Scott et al., 1980; Yordanov, 1983).

\section{References}

ATANASSOVA, B. 1977. Inheritance of the components connected with exserted stigma in tomato F2 and backcross generations. Tomato Genet. Coop., 27, 27-29.

ATANASSOVA, B. 1978. Combining ability with respect to anther length and style in a tomato diallele cross. Genet. Sel., 11, 302-305.

ATANASSOVA, B. AND GEORGIEV, H. 1986. Investigation of tomato male-sterile lines in relation to hybrid seed production. Acta Hortic., 190, 553-557.

BEHARAV, A., PINTHUS, M. J. AND CAHANER, A. 1992. Interaction effects of the Rht 1 and $R h t 2$ dwarfing alleles and background genes on the growth and grain yield of spring wheat (Triticum aestivum L.) Eur. J. Agron., 1, 263-269.

CAHANER, A. AND HLLEL, J. 1980. Estimating heritability and genetic correlation between traits from generations $\mathrm{F} 2$ and F3 of self-fertilizing species: a comparison of three methods. Theor. Appl. Genet., 58, 33-38.

CURRENCE, T. M. 1944. A combination of semi-sterility with two simply inherited characters that can be used to reduce the cost of hybrid tomato seed. Proc. Am. Soc. Hortic. Sci., 44, 403-406.
DIXON, W. J., BROWN, M. B., ENGELMAN, L., FRANE, J. W., HILL, M. A. JENNRICH, R. A. AND TOPPREK, J. D. 1985. BMDP Statistical Software. University of California Press, Berkeley, CA.

ELKIND, Y. AND CAHANER, A. 1986. A mixed model for the effects of single gene, polygenes and their interaction on quantitative traits. 1. The model and experimental design. Theor. Appl. Genet., 72, 377-383.

ELKIND, Y., CAHANER, A. AND KEDÁR, N. 1990. A mixed model for the effects of single gene, polygenes and their interaction on quantitative traits. 2. The effects of the nor gene and polygenes on tomato fruit softness. Heredity, 64, 205-213.

GEORGIEV, K. H. AND ATANASSOVA, B. 1980. Genetic analysis of the characters controlling tomato flower longistyly. Genet. Sel., 13, 126-133.

HANNA, H. Y. 1980. Genetic study of heat tolerance, size of stigma, style and ovary in the tomato, Lycopersicon esculentum. Diss. Abstr. Int., 41, 1182b.

HANNA, H. Y. AND HERNANDEZ, T. P. 1979. Heat tolerance, pistil size inheritance and heterosis in tomatoes. HortScience, 14, 458-459.

LAPUSHNER, D. AND FRANKEL, R. 1967. Practical aspects and the use of male sterility in the production of hybrid tomato seed. Euphytica, 16, 300-310.

LEVY, A., RABINOWITCH, H. D. AND KEDAR, N. 1978. Morphological and physiological characters affecting flower drop and fruit set of tomatoes at high temperatures. Euphytica, 27, 211-218.

PHILOUzE, J. 1969. Etude de deux genes de sterilité male chez la tomate: ms32 et ms35. Ann. Amelior. Plantes, 19, 443-457.

PHILOUZE, J. 1970. Further studies with male-sterile mutants ms32 and ms35. Tomato Genet. Coop., 20, 45.

PHILOUZE, J. 1973. Action of male-sterility genes ms32 and $m s 35$ in different genotypes. Difficulties concerning the use of these two genes. Agron. Trop., 28, 787.

PHILOUZE, J. 1974. Genes marqueurs lies aux genes de sterilite male $m s 32$ et ms 35 chez la tomate. Ann. Amelior. Plantes, 24, 77-82.

RICK, C. M. AND DEMPSEY. W. H. 1969. Position of the stigma in relation to fruit setting of the tomato. Bot. Gaz., 130, 180-186.

RICK, C. M. AND ROBINSON, J. 1951. Inherited defects of floral structure affecting fruitfulness in Lycopersicon esculentum. Am. J. Bot., 38, 639-659.

RUTTENCUTTER, G. E. AND GEORGE, w. L. 1975. Genetics of stigma position. Tomato Genet. Coop., 25, 20-21.

SAS INSTITUTE INC. 1985. SAS User Guide: Statistics, version 5 edition. SAS Institute Inc., Cary, NC.

SCOTT, J. W., WILLIANT, L. AND GEORGE, J. 1980. Breeding and combining ability of heterostylous genotypes for hybrid seed production in Lycopersicon esculentum Mill. Euphytica, 29, 135-144.

SOKAL, R. R. AND ROHLF, F. J. 1981. Biometry. W. H. Freeman, San Francisco, CA.

STEVENS, M. A. AND RICK, C. M. 1986. Genetics and Breeding. In: Atherton, J. K. and Rudich, J. (eds) The Tomato Crop, pp. 35-100. Chapman and Hall, London and New York.

YORDANOV, M. 1983. Heterosis in the tomato. In: Frankel, R. (ed.) Heterosis, Reappraisal of Theory and Practice, pp. 189-219. Springer-Verlag, Berlin and Heidelberg. 